\title{
COBERTURA VACINAL DOS PROFISSIONAIS DE UM CURSO DE ESPECIALIZAÇÃO EM SAÚDE DA FAMÍLIA DO PIAUÍ
}

\author{
Vacinal covering of the professionals of the \\ spcecialization course in family health of piaui \\ Protección vacunal de los profesionales de un curso \\ de especialización en salud de la familia de piauí
}

\begin{abstract}
Resumo
O presente estudo tem como objetivo avaliar a cobertura vacinal dos alunos de um Curso de Especialização em Saúde da Familila do Piauí. A população do estudo foi constituída por todos os 43 alunos da turma: 19 enfermeiros, 13 médicos e 11 cirurgiõesdentistas. Os dados foram coletados em 2004, utilizando-se questionários auto-aplicáveis. Encontrou-se uma cobertura vacinal de $81,3 \%$ para hepatite B, $76 \%$ para a vacina antiamarlica e $65,1 \%$ para dT. Além disso, 25 alunos $(58,1 \%)$ relataram desconhecimento acerca das vacinas preconizadas pelo Programa Nacional de Imunização (PNI). Os resultados mostraram que esses profissionais de saúde não estão adequadamente vacinados, reforçando a necessidade da implantação de uma política sistemática de imunização para eles, tendo como base as normas preconizadas pelo PNI.
\end{abstract}

Palavras-chave: Vacinação. Programas de Imunização. Saúde da família.

\begin{abstract}
This study has as objective to evaluates the vacinal covering of the professionals of a Specialization Course in Family Health of Piauí. The study population was constituted by all the 43 students of the group, which are 19 male nurses, 13 doctors and 11 surgeons dentists. The data were collected in 2004, being used auto-applicable questionnaires. Was met a covering vacinal of $81,3 \%$ for hepatitis $B, 76 \%$ for the vaccine yellow fever and $65,1 \%$ for $\mathrm{dT}$. Besides 25 students $(58,1 \%)$ they told unknowledge concerning the vaccines extolled by PNI. The results shown that these professionals of health are not appropriately vaccinated, reinforcing the need of the implantation of a systematic politics of immunization for these professionals, tends as base the norms extolled by PNI.
\end{abstract}

\section{Resumen}

El presente estudio tiene como objetivo evaluar la protección vacunal de los estudiantes de un Curso de Especialización en salud de la Familia de Piauí-Brasil. La problación del estudio fue constituida por todos los 43 alumnos de la Turma: 19 enfermeros, 13 médicos y 11 cirujanos dentitas. Los datos fueron recolectados en 2004, usándose cuestionarios autoaplicables. Fue encontrada una protección vacunal de $81,3 \%$ para hepatitis B, 76\% para la fiebre amarilla y $65,1 \%$ para dT. Además de eso, 25 estudiantes $(58,1 \%)$ relataron ignorancia acerca de las vacunas preconizadas por el Programa Nacional de Inmunización (PNII). Los resultados revelaron que esos profesionales de saul no están adecuadamente vacunados, reforzando la necesidad de la impantación de una política sistemática de inmunización para ellos, teniendo como base las normas preconizadas por el PNI.
Keywords:

Vaccination. Immunization programs. Family Health.
Palabras clave:

Vacunación. Programas de inmunización. Salud de la familia. 


\section{INTRODUÇÃO}

0 inadequado estado vacinal dos profissionais da área de saúde constitui-se em sério problema de saúde pública. Segundo o Ministério da Saúde, as coberturas vacinais específicas para este grupo estão muito aquém das mínimas necessárias ao controle das doenças evitáveis por imunizantes ${ }^{(1)}$. Tal constatação foi atribuída à falta de conhecimento por parte dos profissionais de saúde, da falta de disponibilidade destes imunobiológicos nos serviços de saúde, bem como pela pouca importância que é dada a esta proteção específica.

É importante ressaltar que a manutenção de imunidade a doenças infecciosas através de vacinas é parte essencial nos programas de controle e prevenção de infecção para profissionais de saúde, os quais devem estar imunizados contra hepatite $B$, sarampo, rubéola, influenza e tétano, porém dependendo da situação, outras vacinas também são indicadas(2).

0 esquema de vacinação adotado pelo Programa Nacional de Imunização (PNI), para profissionais de saúde, é o que segue: hepatite $B$ - três doses de 1 $\mathrm{ml}$, intramuscular com intervalo de 30 dias da 1a para $2 \underline{a}$ dose e 180 dias da $1 \stackrel{a}{a}$ para a 3 3 dose. Dupla viral, (contra sarampo e rubéola) - dose única, 0,5 $\mathrm{ml}$, subcutânea. Influenza - uma dose de 0,5 ml subcutânea, anualmente. $d T$ - três doses de $0,5 \mathrm{ml}$ via intramuscular com intervalos de 60 dias. Reforço a cada 10 anos ou dentro de cinco anos, em caso de gravidez ou ferimentos tetanogênicos ${ }^{(3)}$.

Os profissionais da área de saúde ingressam no mercado de trabalho de forma desordenada, geralmente sem treinamento de biossegurança e sem verificação da sua situação vacinal. Por outro lado, não há uma política bem definida por parte do Ministério da Saúde, em termos de Programa Nacional de Imunização (PNI), quanto à vacinação específica a esse grupo de trabalhadores, sendo dado maior ênfase apenas à vacina contra hepatite $B^{(1)}$.

0 papel do profissional de saúde como transmissor de doenças infecciosas na prática clínica não pode ser desprezado, pois o risco dele não só adquirir, mas também transmitir doenças aumenta caso o emprego de técnicas adequadas, como, por exemplo, lavagem das mãos, não sejam empregadas corretamente(4).

Os profissionais da área de saúde, especialmente médicos, enfermeiros, cirurgiões dentistas, entre outros que trabalham em hospitais, unidades de saúde, ambulatórios ou outros locais afins, por estarem em contato com pacientes ou materiais infectados, na manipulação de sangue e de outros fluídos corporais dos doentes, estão sob riscos constantes de adquirir determinadas infecções imunopreveníveis.

Além disso, fatores tais como a idade cronológica do profissional, o tempo de exercício da profissão, 0 tipo de atividade exercida e a não utilização dos equipamentos de proteção também contribuem para a aquisição destes tipos de infecções, havendo ainda a probabilidade de estes servirem como veículo de transmissão de tais doenças ${ }^{(5)}$ As técnicas de proteção individual, bem como um adequado estado de imunização, minimizam o risco de aquisição de certas doenças infecciosas para os profissionais de saúde, visto que o número de susceptíveis a doenças imunopreveníveis será assim diminuído.

Estudo $^{(5)}$ realizado com estudantes da graduação de medicina da Universidade Federal de Minas Gerais (UFMG) observou que mais de $50 \%$ dos alunos que estavam concluindo o curso já haviam sofrido algum acidente com material contaminado. Destes, mais da metade não comunicaram ao setor responsável sobre 0 acidente. $E$, entre os que comunicaram, 29\% não receberam orientações adequadas. Estudo similar ${ }^{(6)}$ realizado no ano 2000, com 300 estudantes da graduação de medicina da Universidade Federal do Pará, verificou que $74 \%$ freqüentavam setores de risco de contaminação, $41 \%$ já haviam sofrido ferimentos pérfurocortantes e apenas 33\% haviam recebido as três doses da vacina contra hepatite $B$.

Uma pesquisa realizada em um hospital geral de referência de Teresina constatou que cerca de $80 \%$ dos profissionais desconheciam as vacinas preconizadas pelo PNI, para este grupo, o que contribuiu para 0 deficiente estado vacinal do citado grupo, onde as coberturas vacinais variaram de $10,6 \%$ a $87,1 \%{ }^{(7)}$. Somente uma taxa muito elevada de cobertura vacinal permite obter a imunidade de um grupo, situação epidemiológica em que é reduzido, ao mínimo, o risco de adoecer. Cobertura é um indicador que expressa a quantidade de pessoas atendidas por determinado serviço ou ação. No caso, a cobertura vacinal é um indicador que expressa a proporção de pessoas de um grupo alvo que foi vacinada, em um período de tempo. ${ }^{(8)}$

A despeito dos avanços do $\mathrm{PNI}$, sabe-se que não só no Brasil, mas também em outros países, grande parte dos profissionais da área de saúde, embora disponham dos conhecimentos relativos à transmissibilidade das doenças infecto-contagiosas e mesmo cien- 
tes dos riscos a que estão submetidos no seu dia-a-dia por meio do contato direto com a população, não tomam as precauções necessárias à sua proteção individual(9). Por outro lado, o Ministério da Educação e Cultura e o da Saúde não possuem uma política específica de imunoprevenção para os profissionais da saúde.

Destaca-se que, por causa do contato direto com pacientes, estes profissionais estão mais expostos e passiveis de contrair ou disseminar as doenças havendo, portanto, a necessidade de que os mesmos tenham um estado vacinal adequado ao exercício da sua profissão. Assim, têm-se a consciência de que a principal justificativa para a realização deste estudo está na relevância que tem a vacinação como forma de proteger os profissionais das doenças imunopreveníveis.

A proposta deste estudo decorreu da atuação das autoras nas Universidades em que estão inseridas, onde ministram conteúdos sobre vacinação na graduação e pós-graduação, sendo que uma delas é docente do curso em foco. Os alunos que integram o Curso de Especialização em Saúde da Família são enfermeiros, médicos ou cirurgiões-dentista e têm como local de trabalho as unidades básicas de saúde, onde mantêm contato com pessoas com as mais diversas doenças evitáveis por imunizantes. Este fato os coloca na condição de expostos ou de fontes de infecção, e foi 0 que estimulou e direcionou a realização deste estudo, que tem como objetivo levantar a cobertura vacinal dos profissionais em estudo.

\section{METODOLOGIA}

A presente pesquisa caracteriza-se como do tipo descritiva. Optou-se por esta abordagem uma vez que as pesquisas descritivas têm como objetivo primordial as descrições das características de determinados fenômenos ou estabelecimento de relações entre variáveis ${ }^{(10)}$.

A população do estudo foi constituída por todos os 43 profissionais de saúde, alunos de um Curso de Especialização em Saúde da Família em realização no Piauí, entre os quais 19 enfermeiros, 13 médicos e 11 cirurgiões-dentistas. 0 critério de escolha dos integrantes deveu-se ao fato destes profissionais estarem expostos aos riscos de contaminação por doenças imunopreveníveis, em virtude do seu contato diário com pacientes.

A coleta dos dados foi realizada, mediante preenchimento de um questionário auto-aplicado que continha as seguintes variáveis: sexo, idade, categoria pro- fissional, tempo de formação, pós-graduação anterior, vacinas recebidas, motivos para vacinação dos profissionais da área de saúde, informação sobre vacinas preconizadas pelo PNI para profissionais da área de saúde. Com relação às vacinas recebidas, foi considerada a informação verbal, em virtude da indisponibilidade dos cartões de vacina destes profissionais.

É importante ressaltar que em obediência às exigências da Resolução 196/96, do Conselho Nacional de Saúde ${ }^{(11)}$, foi solicitado o consentimento expresso da população estudada, bem como aprovação do Comitê de Ética da Instituição.

A discussão dos dados coletados foi realizada à luz do conhecimento produzido na literatura relativa ao objeto do estudo. A análise estatística foi feita por meio da distribuição de freqüências e freqüências percentuais simples.

\section{RESULTADOS E DISCUSSÕES}

0 estudo permitiu verificar que o risco de contrair infecções por doenças imunopreveníveis entre os profissionais de saúde é significativo, em face da incompletude dos seus esquemas de vacinação, apontando ainda que, mesmo após o ingresso no mercado de trabalho, esses profissionais continuam sem a necessária proteção.

Tabela 1 - Caracterização da População do estudo. Teresina Piauí, 2004

\begin{tabular}{lcc}
\hline \multicolumn{1}{c}{ Variáveis } & \multicolumn{2}{c}{ Freqüência } \\
\cline { 2 - 3 } & $\mathbf{N}$ & $\%$ \\
\hline Sexo & 12 & 27,9 \\
Masculino & 31 & 72,09 \\
Feminino & & \\
Idade & & \\
26 a 30 anos & 16 & 37,2 \\
31 a 40 anos & 14 & 32,5 \\
41 a 50 anos & 08 & 18,6 \\
> 50 anos & 05 & 11,6 \\
Categoria Profissional & & \\
Enfermeiro & 19 & 44,1 \\
Médico & 13 & 30,2 \\
Cirurgião-dentista & 11 & 25,5 \\
Tempo de Formaçäo em anos & & \\
3 anos a 10 anos & 27 & 62,7 \\
11 a 20 & 12 & 27,9 \\
21 a 30 anos & 03 & 6,9 \\
> 30 anos & 03 & 6,9 \\
Pós-Graduação Anterior & & \\
Nenhuma & & \\
Especialização & 33 & 76,7 \\
Residência & 06 & 13,9 \\
\hline
\end{tabular}


Pela tabela 1, observa-se que $72 \%$ eram do sexo feminino, mais da metade dos alunos tinham menos de 40 anos e $44 \%$ eram enfermeiros. $62 \%$ dos alunos tinham de três a dez anos de formados e cerca de $76 \%$ não tinham realizado nenhuma pós-graduação anterior; $13,9 \%$ já tinham alguma especialização e 4,6\% tinham cursado residência.

Gráfico 1 - Cobertura Vacinal da População do Estudo por Imunobiológico. Teresina/PI 2004

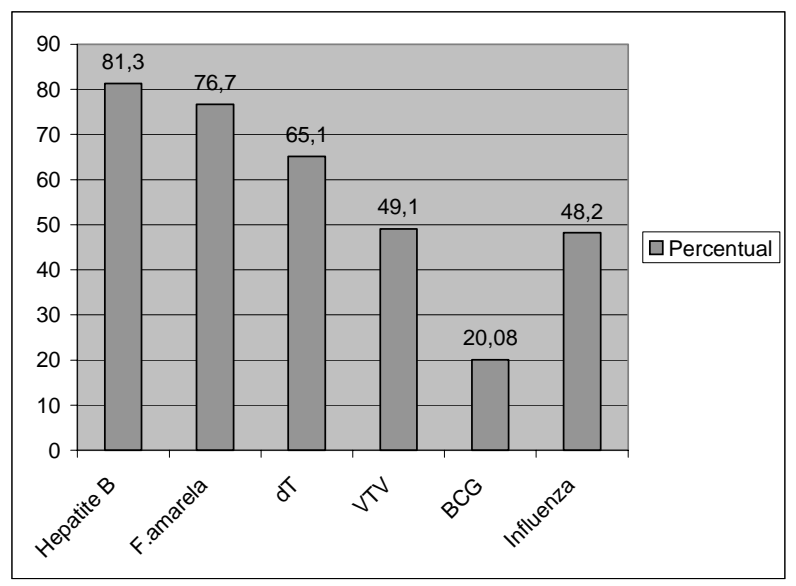

0 gráfico 1 mostra que a cobertura vacinal dos profissionais do estudo variou de acordo com 0 imunobiológico. A maior cobertura foi identificada para a vacina da hepatite $B(81,3 \%)$, seguida da vacina antiamarílica e da dT com coberturas de 76,7\% e $65,1 \%$, respectivamente. Tais resultados para a hepatite B são compatíveis com a política de vacinação do Ministério da Saúde, que vem realizando, de forma sistemática e contínua, ampla divulgação e implementação da vacinação contra hepatite B para os profissionais de saúde, entre outros grupos de risco. Ressalta-se, porém, que o percentual de suscetíveis, mesmo para hepatite $B$, cuja cobertura vacinal foi a mais alta encontrada no grupo, ainda é consideravelmente grande $(18,7 \%)$.

No tocante à cobertura com dT, pode-se inferir que as coberturas encontradas devem-se ao fato da grande maioria da população do estudo ser do sexo feminino $(72,0 \%)$ e na sua totalidade em idade fértil, por conseguinte têm dupla indicação para receber esta vacina. É importante acrescentar que o Ministério da Saúde vem desenvolvendo campanha de vacinação em massa contra difteria e tétano para mulheres em idade fértil de todo o país.
Com relação à vacina antiamarílica, as coberturas justificam-se por se tratar de uma vacina obrigatória em 53 municípios do Estado, considerados de risco para a febre amarela, por terem situação geográfica limítrofe com áreas endêmicas. Outro fato que contribuiu para esta cobertura foi a realização de uma campanha vacinal indiscriminada contra a febre amarela no Estado, no ano de 2000.

Tabela 2 - Distribuição das vacinas mais indicadas para os profissionais da área de saúde, na concepção da população do estudo. Teresina/PI - 2004

\begin{tabular}{ccccccc}
\hline & \multicolumn{6}{c}{ População do Estudo } \\
\cline { 2 - 7 } Vacinas & Enfermeiro & \multicolumn{1}{c}{ C. Dentista } & \multicolumn{2}{c}{ Médico } \\
\hline & $\mathbf{N} \mathbf{0}$ & $\%$ & $\mathbf{N} \mathbf{0}$ & $\%$ & $\mathbf{N} 0$ & $\%$ \\
\cline { 2 - 7 } BCG & 15 & 78,9 & 04 & 36,3 & 09 & 6,9 \\
DPT & 01 & 5,2 & 04 & 36,3 & 03 & 23 \\
Influenza & 10 & 52,6 & 03 & 27,2 & 08 & 61,5 \\
dT & 15 & 78,9 & 05 & 45,4 & 09 & 69,2 \\
Dup. ou Tríplice Viral & 10 & 52,6 & 01 & 9,0 & 01 & 7,6 \\
Anti-amarílica & 08 & 42,1 & 01 & 9,0 & 01 & 7,6 \\
Anti-hepatite B & 19 & 100 & 11 & 100 & 13 & 100 \\
Anti-varicela & 09 & 47,3 & - & 00 & 02 & 15,3 \\
Anti-meningocócica & 01 & 5,2 & 03 & 27,2 & 01 & 7,6 \\
Todas & 03 & 15,7 & 03 & 27,2 & 02 & 15,3 \\
\hline
\end{tabular}

Ao serem perguntados sobre as vacinas que deveriam ser administradas aos profissionais de saúde, três delas foram as mais citadas: Hepatite B: 100\% das três categorias profissionais; BCG: 78,9\% dos enfermeiros e $36,3 \%$ dos cirurgiões-dentistas e $69,2 \%$ dos médicos; dT: 78,9\% dos enfermeiros, 45,4\% dos cirurgiões-dentistas e 69,2\% dos médicos.

Observa-se que houve consenso apenas com relação à vacina contra hepatite $B$. Outro ponto que merece realce é que o enfermeiro foi o profissional, entre os que participaram do estudo, que mostrou mais conhecimento com relação às verdadeiras indicações à vacinação, possivelmente pelo maior envolvimento com as atividades de vacinação e pela maior participação nas capacitações voltadas para esta área técnica.

Destaca-se também a varicela, sugerida por poucos profissionais. Recente trabalho sobre a soroepidemiologia da varicela, realizado em capitais brasileiras, demonstrou que $8 \%$ dos adultos, entre 21 a 30 anos de idade, são soronegativos. ${ }^{(12)}$ 
Tabela 3: Distribuição dos motivos apresentados pela população do estudo para a vacinação dos profissionais de saúde. TeresinaPiauí, 2004

\begin{tabular}{|c|c|c|c|c|c|c|}
\hline \multirow{3}{*}{ Motivos } & \multicolumn{6}{|c|}{ População do Estudo } \\
\hline & \multicolumn{2}{|c|}{ Enfermeiro } & \multicolumn{2}{|c|}{ Dentista } & \multicolumn{2}{|c|}{ Médico } \\
\hline & № & $\%$ & № & $\%$ & № & $\%$ \\
\hline $\begin{array}{l}\text { Contato com pacientes } \\
\text { portadores de doenças/ } \\
\text { contaminados }\end{array}$ & 19 & 100 & 8 & 72,7 & 6 & 42,1 \\
\hline Risco de contrair doenças & 19 & 100 & 10 & 90,08 & 10 & 76,09 \\
\hline $\begin{array}{l}\text { Imunização/prevenção/ } \\
\text { proteção }\end{array}$ & 19 & 100 & 02 & 18,1 & 01 & 7,7 \\
\hline $\begin{array}{l}\text { Risco de transmitir } \\
\text { doenças imunopreveníveis }\end{array}$ & 13 & 68,4 & 01 & 9,0 & 04 & 30,7 \\
\hline
\end{tabular}

Quando perguntados sobre os motivos para 0 uso das vacinas, $100 \%$ dos enfermeiros responderam ser devido ao contato com possíveis pacientes portadores de doenças/contaminados, risco de contrair doenças e imunização/prevenção/proteção; Os cirurgiões-dentistas e médicos responderam ser devido ao risco de contrair doenças/exposição e risco de transmitir doenças imunopreveníveis.

Observa-se que os pesquisados têm consciência do risco ao qual estão expostos no ambiente de trabalho, mesmo porque 0 risco de contrair doenças depende não só do tipo de acidente e da profilaxia pós-exposição, como da prevalência local de doenças e da susceptibilidade do acidentado. Por outro lado, observamos que poucos têm a consciência de que podem se constituir em agentes transmissores de doenças e, por conseguinte, podem levar os usuários à condição de expostos.

Tabela 4 - Distribuição das categorias profissionais do estudo segundo informação sobre as vacinas preconizadas pelo PNI para os profissionais de saúde. Teresina-Piauí, 2004

\begin{tabular}{ccccc}
\hline Categoria Profissional & \multicolumn{3}{c}{$\begin{array}{c}\text { Informação sobre as } \\
\text { vacinas preconizadas para } \\
\text { os profissionais de saúde }\end{array}$} \\
\cline { 2 - 6 } & \multicolumn{2}{c}{ Sim } & \multicolumn{2}{c}{ Não } \\
\hline Enfermeiro & 13 & 68,4 & 06 & 31,6 \\
C. Dentista & 01 & 9,0 & 10 & 90,9 \\
Médico & 04 & 30,8 & 09 & 69,2 \\
\hline
\end{tabular}

A tabela 4 mostra que $31,63 \%$ dos enfermeiros, $90,9 \%$ dos cirurgiões-dentistas e $69,2 \%$ dos médicos não tinham informação sobre quais as vacinas que 0 PNI preconiza para os profissionais de saúde, o que representa uma grande lacuna no conhecimento. Este dado aponta para a insuficiente implementação de campanhas educacionais sobre prevenção de doenças imunopreveníveis, para os profissionais de saúde em geral.

Tabela 5 - Vacinas preconizadas pelo PNI para profissionais de saúde, segundo informação das categorias profissionais estudadas. Teresina/PI - 2004.

\begin{tabular}{cccccccc}
\hline & \multicolumn{6}{c}{ População do Estudo } \\
\cline { 2 - 8 } Vacinas & \multicolumn{1}{c}{ Enfermeiro } & C. & Dentista & \multicolumn{2}{c}{ Médico } \\
\hline & No & $\%$ & No & $\%$ & No & $\%$ \\
\hline Anti-hepatite B & 19 & 100 & 11 & 100 & 13 & 100 \\
Anti-amarílica & 05 & 26,3 & 01 & 9,0 & 01 & 7,7 \\
DT & 13 & 68,4 & 03 & 27,2 & 03 & 23 \\
Influenza & 03 & 15,8 & 01 & 9,0 & 02 & 15,3 \\
BCG & 07 & 36,8 & 01 & 9,0 & 02 & 15,3 \\
D. ou Tríplice Viral & 10 & 52,2 & 0 & 00 & 02 & 15,3 \\
\hline
\end{tabular}

De acordo com a tabela acima, observa-se que grande parte dos respondentes dispõe de informação muito limitada sobre quais vacinas são preconizadas pelo PNI para os profissionais de saúde, visto que nenhum deles relacionou-as corretamente. 0 grupo de enfermeiros foi o que mais se aproximou, ainda assim, apenas para as vacinas hepatite B $(100 \%)$, dT $(68,4 \%)$ e dupla ou tríplice viral $(52,5 \%)$, o que denota a falta de campanhas de esclarecimento dirigidas a esses profissionais, visando sensibilizá-los da necessidade de estarem imunizados, haja vista que a imunização é uma das estratégias mais eficazes na luta contra as doenças imunopreveniíveis.

\section{CONSIDERAÇÕES FINAIS}

Pela análise dos resultados, pode-se concluir que os alunos do Curso de Especialização em Saúde da Família do estudo não estão adequadamente imunizados estando, consequentemente, suscetíveis de adquirir e transmitir doenças imunopreveníveis. A vacina contra hepatite $B$ foi a que apresentou melhor cobertura no grupo estudado $(81,3 \%)$. Os dados demonstram também que $58,1 \%$ dos pesquisados não têm nenhuma informação sobre quais vacinas estão preconizadas pelo PNI para os profissionais de saúde. Considerando-se as três categorias profissionais estudadas, observa-se que a deficiência desse tipo de informação é maior entre os cirurgiõesdentistas $(90,9 \%)$. Infere-se daí que, possivelmente, a faIha esteja relacionada à falta de campanhas educativas direcionadas a esses profissionais, bem como ao menor envolvimento desses, pela própria natureza das suas atividades, com as ações relacionadas com a vacinação. 
0 estudo demonstrou, ainda, que poucos têm a consciência de que podem constituir-se em agentes transmissores de doenças e, por conseguinte, podem levar os usuários à condição de expostos. Os riscos de contrair e transmitir infecção por doenças imunopreveníveis, entre os profissionais da área de saúde, começam ainda nas atividades acadêmicas, não sendo adequado aguardar-se 0 ingresso na vida profissional para iniciar a vacinação(13).

É importante a compreensão de que não é suficiente uma simples orientação dos estudantes e profissionais sobre a necessidade da imunização, ${ }^{(14}$ 15) devendo ser implantado um programa mais agressivo de exigência de cumprimento do esquema vacinal, para obtenção de coberturas mais adequadas.

Uma das razões que podem explicar a deficiente cobertura vacinal dos profissionais de saúde poderia ser 0 fato de que as recomendações técnicas, quando existentes, estão dispersas em vários documentos diferentes, 0 que tem dificultado 0 acesso à informação ${ }^{(5,14)}$.

Considerando-se os aspectos relatados, o momento ideal para a vacinação dos profissionais de saúde é antes mesmo de concluir a graduação, mais especificamente antes de ingressar nos estágios, levando-se em conta que o treinando apresenta um risco ainda maior de contaminação que o profissional experiente.

Desse modo, faz-se necessário a implantação de uma política sistemática de imunização, com determinação de um calendário básico no âmbito nacional, para os estudantes e profissionais de saúde, como também campanhas educacionais sobre as doenças imunopreveníveis, o que por certo virá contribuir para a melhoria da cobertura vacinal desses profissionais.

\section{Referências}

1. Ribeiro JGL Necessidade de adoção de uma política de imunização para acadêmicos de medicina: a situação da Faculdade de Ciências Médicas de Minas Gerais. [ dissertação de mestrado]. Belo Horizonte (MG): Faculdades de Ciências Médicas/UFMG; 2002.

2.Centers for Desease Control and Prevention. Multidrug-resistant tuberculosis in a hospital-Jersey:1990-1992. Morbidity and Mortality Weeldy Report 1994; 43 (3): 15- 28.

3.Ministério da Saúde (BR). Manual de normas de vacinação. 3å ed. Brasilia (DF); 2001.

4.Person ML et al. Nosocomial transmission of multidrug-resistant Mycobacterium tuberculosis: a risk and health care workers. Ann Intern Med 1997; 117: 101-105.

5. Oliveira SMVL. Exposição ocupacional a sangue e/ ou fluidos orgânicos no Hospital da Universidade Federal do Mato Grosso do Sul. Rev Soc Bras Med Trop 2001; 34 (1): 418-22.

6. Ribeiro MB . Avaliação dos riscos de contaminação pelo vírus da hepatite $B$, na prática acadêmica, entre os estudantes de medicina da Universidade Federal do Pará. Rev Soc Bras Med Trop 2001; 34 (1) : 323-25.

7.0liveira CU. Estado vacinal dos profissionais de saúde do Hospital Getúlio Vargas. [monografia de conclusão do curso]. Teresina (PI): Escola de Enfermagem/UFPI; 2004.

8. Imunização de profissionais de saúde. Boletim Informativo Publicações n 123. [on line] 2004 [citado 24 jan 2004]; Disponível em: http://www.bibliomed.com.br .

9. Organização Pan-Americana de Saúde/ OPAS. 25a Reunião do grupo técnico assessor em doenças preveníveis por vacinação. Melhorando os serviços de imunizações. conclusões e recomendações. Washington DC(EUA); 2002.

10. Richardson RJP. Pesquisa social: métodos e técnicas. 3a ed. São Paulo (SP): Atlas; 1999.
11. Conselho Nacional de Saúde (BR). Resolução no 196/96. Diretrizes e normas regulamentadoras de pesquisa envolvendo seres humanos.; Brasília (DF); 1996.

12. Clemens, SAC. et al. Soroepidemiologia da varicela no Brasil: resultados de um estudo prospectivo transversal. Morbidity and Mortality Weeldy Report 1999; 75 (6): 433-44

13. Rampinelle CA. Estudo descritivo dos acidentes com material potencialmente contaminado com sangue em ambiente hospitalar entre estudantes de medicina. Rev Soc Bras Med Trop 2000; 33 (1): 257-58.

14. Hasegawa, EM; Lopes, MH; Gutierrez, EB. Avaliação de programa de vacinação para estudantes de medicina. Boletim da Sociedade Brasileira de Imunizações 2001; 3 (4): 4-8.

15. Farias AHT; Henriques SL. Diferentes níveis de proteção à hepatite $B$ entre profissionais de saúde: prevenção primária deve melhorar. Rev Soc Bras Med Trop 2000; 33(1): 302-04.

\section{Sobre as Autoras}

\section{Telma Maria Evangelista de Araújo}

Enfermeira, Mestre em Enfermagem, Doutoranda da Escola de Enfermagem Anna Nery/UFRJ, Professora da UFPI.

\section{Elizabete Pimenta Araújo Paz}

Enfermeira, Doutora em Enfermagem, Professora Adjunta da Escola de Enfermagem Anna Nery/UFR].

\section{Rosane Harter Griep}

Enfermeira, Doutora em Enfermagem, Professora Adjunta da Escola de Enfermagem Anna Nery/UFRJ. 